\title{
Micromorphological features of humus plasma formation in ornitogenic soils of Maritime Antarctica (North-West part of Antarctic peninsula region)
}

Abakumov E.

Department of Applied Ecology, Saint-Petersburg State University, Saint-Petersburg, Russia, e_abakumov@mail.ru, e.abakumov@spbu.ru

doi: 10.36291/HIT.2019.abakumov.021

Soil cover of the Antarctic characterizes by relatively low thickness and spatial discontinuity of the superficial organo-mineral bodies and the absence of the most of the features that are specific for the "normal" soils (even for the high latitudes of the northern hemisphere). That is why micromorphological method is considered as most suitable for investigation of pedogenic features in the soils of Antarctica [1, 2, 3]. Soils, located on the Ardley Island, Fildes Peninsula were selected for fine sections monoliths sampling. One soil is normal organo-mineral soils under organic remnants of cereal plant - Deshampsia antarctica (62-14-385 S, 58-58-486 W). Second soil was sampled under recent penguin rockeries, which is now abandoned and faced to colonization of algae - Prasiola crispa and cereal plant - Deshampsia antarctica (62-14-391 S, 58-580549 W). Soil samples were air-dried and being passed through a 1-mm sieve for further chemical analyses. Fine sections of soil material were prepared form micro monoliths of soils, sampled in field. Samples were dried and saturated with resin. Thin sections were investigated with use of polarization microscope Leica DM $750 \mathrm{p}$ in transmitted light and crossed nicols. The following soil micromorphological indexes have been investigated: soil microfabric, spatial arrangements of fabric units, soil particles distribution, elements of microstructure and character of organic matter. Soil formed under pure plant remnants without admixture of guano showed formation of humus plasma on the surface of primary minerals. This plasma forms the films or stains of organic matter, coating the mineral substrate. These morphological formations can be considered as initial signs of pedogenesis. The more developed stage of biogenic-abiogenic interactions is formation of soil aggregates, cemented by humic materials. This type of interactions is more typical for superficial layers of soils, formed under the sod horizons in locations of Deshampsia antarctica. Soils, formed under guano showed formation of specific organic plasma, derived from organic remnant of guano. This plasma plays an important role in aggregation of silt and sandy particles and their stabilization on the surface of soils, which important in conditions of stormy winds, and finally results in formation of stable soil cover on the territory of penguin rockeries. Moreover, the guano plasma coatings penetrate into the deepest soil horizons and result in enriching of all soil horizons by organic matter and mineral nutrients. This is a reason of initiation of humification in all horizons of soil, affected by ornitogenic effect on the topsoil layer. Thus, organic matter which is invisible on the macroscale, exist in soils of various environment of Antarctica and can be fruitfully investigated with the use of modern microscopic methods.

Acknowledgments. This work was supported by Russian Foundation for Basic Research, project № 18-04-00900 "Ornitogenic soils of Antarctica: formation, geography and biogeochemistry" and Saint Petersburg State University Internal Grant for the Modernization of Scientific Equipment No. 1.40.541.2017.

References

1. Ilieva R. et al. // Bulgarian J. Ecolog. Sci. 2003. 2(304):52-54.

2. Kubiena W.L. // Antarctic J. 1970. 5(4):105-106.

3. Mergelov et al. // Sci. Reports. 2018. 8(1): paper № 3367. 